\title{
Reciclagem e Aplicações da Borracha Sintética de Chinelos Descartados no Design de Produtos
}

\author{
Recycling and Applications of Synthetic Rubber Discarded Slippers in Product Design
}

DIAS, Joner de Lima; Mestrando; Programa de Pós-graduação em Sustentabilidade; Universidade Estadual de Maringá/Instituto Federal do Paraná

jldias2@uem.br

FORCATO, Marcelo dos Santos; Doutorando; Universidade Estadual de Maringá; Programa de Pósgraduação em Design / FAAC; Universidade Estadual Paulista

msforcato2@uem.br

DALBERTO, Anelise Guadagnin; Mestre; Universidade Estadual de Maringá

agdalberto2@uem.br

ORTIZ, Guilherme Clausem; Graduado; Universidade Estadual de Maringá

\section{Resumo}

Este artigo apresenta resultados obtidos por projeto de pesquisa que objetivou investigar e desenvolver material proveniente de resíduos sólidos de borracha sintética de chinelos descartados. Com a utilização deste resíduo em estado de pó, foram realizados testes com aglutinantes artificiais e vegetais que formaram alternativas de materiais que posteriormente foram submetidos a testes químicos e físicos. Como resultados, obtiveram-se três materiais experimentais que utilizam aglutinantes de baixo impacto ambiental. Neste artigo são apresentados os materiais obtidos bem como a comparação entre as características e propriedades de cada material, além de suas possibilidades de aplicação no design de produtos.

Palavras Chave:resíduo sólido, borracha de chinelos descartados, material experimental, design de produtos.

\begin{abstract}
This article presents results of a research project that aims to investigate and develop material from solid waste synthetic rubber discarded slippers. With the use of this residue in a powdered state, tests were carried out with artificial and vegetable binders that formed alternative materials that were subsequently subjected to chemical and physical tests. As results, three experimental materials were obtained using low environmental impact binders. This article presents the materials obtained as well as the comparison between the characteristics and properties of each material, besides its possibilities of application in the design of products.
\end{abstract}

Keywords: solid waste, ruber discarded slippers, experimental material, product design.

\section{Introdução}

Amplamente utilizada em produtos industriais, as borrachas estão presentes em diversos tipos de produtos industriais, sendo mais utilizadas em pneus, revestimentos de cabos elétricos e 
eletrônicos, recipientes, calçados, brinquedos, produtos para vedação, luvas e outros produtos de uso individual. As principais características que a difere dos demais materiais são o potencial elevado de estiramento e sua resiliência (LIMA, 2013). Dentre outras propriedades e características, as borrachas se destacam ainda por sua resistência à abrasão, resistência a corrosão e impermeabilidade, além do material permitir mistura com outras substâncias ou materiais para melhorar seu desempenho (PAPAUTSKY, 2003).

Genericamente, as borrachas são classificadas como borracha natural e borrachas sintéticas. Borracha natural são aquelas produzidas por meio da extração da seiva das árvores seringueiras. Amplamente utilizado, o material possibilitou o desenvolvimento econômico da região Norte do Brasil a partir do século XIX. As borrachas sintéticas são elastômeros obtidos pela síntese da borracha, ou seja, é uma borracha artificial. Descoberta em 1875, sua produção em massa só foi iniciada a partir da Segunda Guerra Mundial, com o crescimento da demanda por este material. Com características inferiores às da borracha natural, a produção de borracha artificial é mais rápida, tornando o material mais barato (MUCAMBO, 2015).

Segundo Statista (2016), a produção de borracha sintética vem crescendo sensivelmente ao longo dos anos (Figura 1 ).

Figura 1 - Produção global de borracha sintética entre os anos de 2000 e 2014.

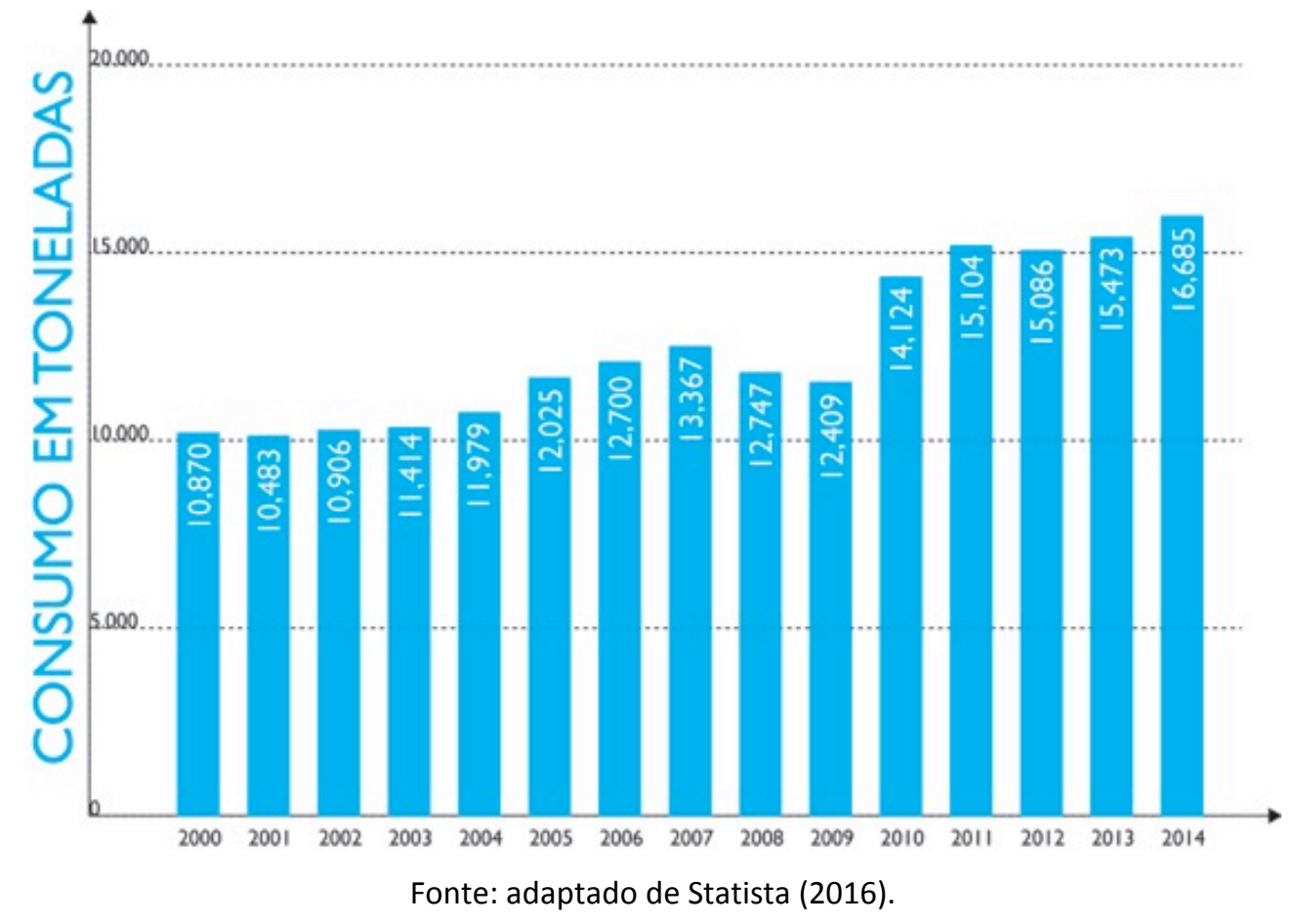

Acredita-se que um dos motivos deste crescimento seja a facilidade na produção da borracha sintética se comparada com a da borracha natural. Entretanto, o aumento da produção da borracha sintética, mostra uma situação de demanda que afeta diretamente o meio ambiente. A borracha sintética é derivada do petróleo e sabe-se que o petróleo é um bem não renovável. Soma-se a isto o fato deste material, quando descartado, ter prazo indeterminado de absorção pela natureza (FORCATO et. al., 2017). 
Relacionado ao volume de produção setorial da borracha, em 2013, do total de borracha sintética produzida, $68 \%$ foi utilizada pela indústria de pneus, $9 \%$ para produção de artigos mecânicos, $8 \%$ na produção de outros produtos automotivos, 5\% pela indústria de calçados, 5\% pela construção civil, sendo o restante para produção de outros produtos diversos (GLOBAL RUBBER MARKETS, 2014).

Nunes (2015) explica que mesmo havendo a possibilidade de reciclagem da borracha sintética, nota-se um atrasodo Brasil se comparado a outros países. Tal atraso é mais significativo se for desconsiderada areciclagem de pneus focando-se nos outros produtos fabricados em borracha. No Brasil, oparque industrial de produção de borracha está defasado. Para facilitar a reciclagem umamodernização tecnológica e da gestão da produção deveria ser feita, facilitando, portanto, oreaproveitamento. As novas gerações vêm aumentando a sua preocupação com o impacto dosobjetos no meio ambiente, e consequentemente suas decisões de compra podem serinfluenciadas por tal preocupação. Além disso, o descarte de produtos de borracha deve serlevado a sério pela indústria que deve investir na reciclagem de seus produtos e pensar emformas alternativas para o ciclo de vida de produtos que atingiram o final de sua vida útil(NUNES, 2015).

Com relação à indústria de borracha, inclusive à produção de pneus, algumasestatísticas apontadas por Brown (2008) apudForrest (2014) assinalaram que o total deborracha reciclada mundialmente quando os produtos chegam ao fim da vida útil estava entre $3 \%$ e $15 \%$ em 2014; com relação ao montante de borracha reutilizada de alguma forma os númerosficavam entre $5 \%$ e 23\% (BROWN, 2008 apud FORREST, 2014).

Tratando-se da indústria brasileira de pneus, $90 \%$ dos pneus são reaproveitados,entretanto, existe um atraso se for desconsiderada a reciclagem de outros produtos feitos deborracha. 0 montante de resíduos gerados pela indústria de artefatos de borracha é jogado ematerros e poucas indústrias desse setor se preocupam com os refugos, fato que contribui para afalta de um dimensionamento e impactos dos produtos de borracha, com exceção dos pneus.Calcula-se que o montante de refugo de borracha no Brasil esteja entre $15 \%$ e 20\%, valorconsiderado extremamente elevado (NUNES, 2015).

Existe também a questão do desperdício nas indústrias, nos processos produtivos,mostrando a necessidade de uma revisão na cadeia de produção e o incentivo da criação deciclos que evitem o desperdício de material. Segundo o autor, processos como moldagem porinjeção geram um desperdício que fica entre $30 \%$ e $50 \%$. Já o processo de extrusão gera umdesperdício que varia de $2 \%$ a $5 \%$ e o desperdício em processos finais como estamparia (depeças como juntas em lâminas de borracha) está entre $20 \%$ e $40 \%$ aproximadamente(BROWN, 2008 apud FORREST, 2014).

\section{O Setor Calçadista e sua Geração de Resíduos}

Soma-se ao já exposto o fato do setor calçadista ser destaque na economia brasileira. 0 país é oprincipal produtor no continente americano e sua produção é principalmente voltada para omercado interno. Entretanto, o país busca melhorar suas indústrias calçadistas e expandir seucomércio para combater a concorrência do mercado asiático (GUIDOLIN et. al., 2010).

Na década de 1990, o setor calçadista brasileiro sofreu com a inserção do mercadoasiático que oferecia um produto mais barato. Com isso, muitas empresas calçadistas noBrasil mudaram 
suas fábricas para o Nordeste devido a incentivos fiscais e custo da mão-de-obrareduzida. Como resultado, foi estabelecido no Brasil dois modelos para o setorcalçadista: um deles é mais tradicional localizado no Sudeste e Sul do Brasil, onde as produções são feitas por pequenas e médias empresas, voltadas a públicos reduzidos sendo que sua produção não possui extrema abrangência; o outro modelo, concentrado no Nordeste, compreende empresas de grande porte que buscam nessa região ferramentas para concorrer com produtos internacionais. No gráfico abaixo (Figura 2) é possível ver essa diferença nos dois modelos ao analisar a relação dos estados com o porte das empresas (em número de empregados) (GUIDOLIN et. al., 2010).

Figura 2 - Principais estados brasileiros produtores de calçados em 2008.

\begin{tabular}{|c|c|c|c|}
\hline \multicolumn{4}{|c|}{$\begin{array}{l}\text { ESTADOS BRASILEIROS } \\
\text { PRODUTORES DE CALÇADOS }\end{array}$} \\
\hline ESTADOS & EMPREGADOS & ESTABELECIMENTOS & $\begin{array}{c}\text { ESTADOS/ } \\
\text { ESTABELECIMENTOS }\end{array}$ \\
\hline $\begin{array}{l}\text { RIO GRANDE } \\
\text { DO SUL. }\end{array}$ & 106.225 & 3.285 & 32,3 \\
\hline CEARÁ & 49.561 & 287 & 172,7 \\
\hline SÃO PAULO & 47.732 & 2.912 & 16,4 \\
\hline BAHIA & 31.408 & 132 & 237,9 \\
\hline MINAS GERAIS & 24.654 & 1.572 & 15,7 \\
\hline PARAíBA & 12.077 & 114 & 105,9 \\
\hline $\begin{array}{l}\text { SANTA } \\
\text { CATARINA }\end{array}$ & 7.143 & 339 & 21,1 \\
\hline SERGIPE & 3.364 & 14 & 240,3 \\
\hline PARANÁ & 2.608 & 149 & 17,5 \\
\hline PERNANBUCO & 1.613 & 61 & 26,4 \\
\hline GOIÁS & 1.529 & 209 & 7,3 \\
\hline DEMAIS ESTADOS & 5.326 & 238 & 223,2 \\
\hline TOTAL & 293.240 & 9.312 & 31,5 \\
\hline
\end{tabular}

Fonte: adaptado de RAIS [Brasil (2009)].

Em escala internacional, o Brasil é o terceiro maior produtor de calçados, sendo que em 2008 o país produziu 804 milhões de calçados e $80 \%$ da quantidade produzida foi consumida internamente. Além disso, a produção brasileira é muito concentrada em calçados de plástico e borracha com enfoque para os chinelos de plástico/borracha que é o único setor calçadista brasileiro que mostrou crescimento em anos anteriores em relação aos outros tipos de calçados como pode ser visto na Figura 3 (GUIDOLIN et. al., 2010).

É possível notar que o Brasil possui grande destaque na produção de calçados e que sua produção é voltada principalmente para o mercado interno. Por um lado, isso mostra como o setor calçadista do Brasil possui capacidade de atender ao seu próprio público e suprir a necessidade por calçados. Mas por outro lado, sendo a maioria da produção destinada ao mercado interno, os impactos desta, as causas de uma gestão ruim dos resíduos e dos descartes dos produtos finais, refletem também internamente. Garlet (1998) corrobora mencionando que a 
produção calçadista brasileira é muito conhecida pelo seu destaque no mercado nacional e internacional, mas que esse setor também é muito conhecido pela geração de resíduos e pela falta da existência de programas para a reciclagem dos materiais que fazem parte desta cadeia.

Figura 3 - Produção brasileira por tipo de calçado de 2003 a 2007.

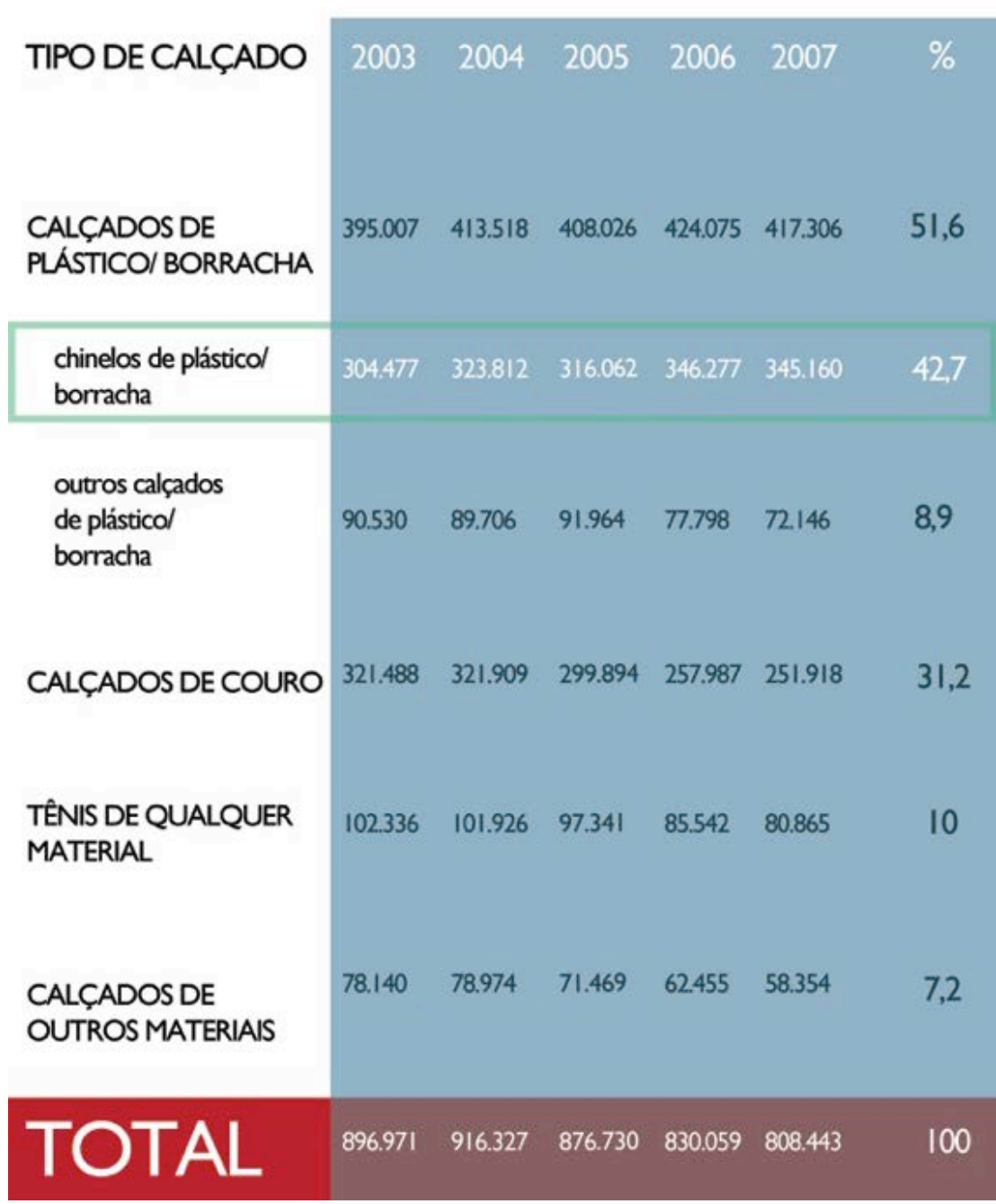

Fonte: adaptado de RAIS [Brasil (2009)]

O número de pesquisas com enfoque na reutilização de resíduos gerados no processo produtivo tem crescido devido ao aumento dos resíduos gerados pela indústria e a diminuição da área para a deposição desses dejetos (RAMASW et. al., 1983 apud GARLET, 1998).

Existem três principais motivos que estimulam o crescimento de pesquisas na área de reaproveitamento destes resíduos pela indústria como: o esgotamento dos pontos de origem da matéria-prima; preocupação com a preservação do meio ambiente; e necessidade de conseguir independência de matérias primas monopolizadas (petróleo) (CINCOTTO, 1990 apud GARLET, 1998).

Portanto, considerando fatores como: a defasagem da indústria da borracha no Brasil; a necessidade de repensar as estratégias de produção e descarte de matéria prima; o volume de 
produção de calçados, principalmente de chinelos de borracha bem como o descarte destes produtos e materiais no pós-uso; e ainda a necessidade de se obter alternativas menos impactantes nas fases de produção e utilização dos produtos pelo usuário, objetivou-se nesta pesquisa estudar a fase final do ciclo de vida da borracha, mais especificamente aquela referente aos chinelos, com o intuito de identificar formas viáveis de reciclagem deste material reinserindoo no design de produtos. A justificativa para a escolha dos resíduos de chinelos se deu pela expressiva diferença entre o volume de produção de chinelos de borracha em relação aos demais tipos de calçados (FORCATO et. al., 2017).

Em se tratando do lixo gerado pelo setor calçadista, é preciso entender como essasituação acontece e quais seriam os motivos para não existir um tratamento para o lixo geradopelos seus descartes.O Brasil produz aproximadamente 76 milhões de toneladas de lixo por ano, e teriacapacidade de reciclar cerca de $30 \%$ do lixo produzido. Entretanto, apenas $3 \%$ do lixobrasileiro são reciclados. Além disso, houve um crescimento de municípios que aderiram aprogramas sustentáveis, mas o total não atinge $20 \%$ das cidades brasileiras. Profissionais nosprogramas de reciclagem apontam para uma falta de integração entre os diversos setores dasociedade (PAIVA, 2015).

Além disso, dados de pesquisa realizada em 2015 pela Associação Brasileira deEmpresas de Limpeza Pública e Resíduos Especiais - ABRELPE, sobre a gestão dos resíduosbrasileiros, apontam crescimento alarmante da produção de resíduos. Entre os anos de 2003 a2014 (período de abrangência da referida pesquisa) a produção de resíduos cresceu $29 \%$ sendo que o crescimento populacional no mesmo período foi de $6 \%$. Outro dado importantefoi o total de lixo destinado a aterros sanitários no Brasil, 58,4\%. Soma-se a isto o fato de quemais de 20 milhões de brasileiros não possuem um serviço de coleta regular de resíduos, jáque $10 \%$ dos resíduos gerados não são nem recolhidos. Isso mostra que por mais que sejamcriados programas de tratamento de lixo os mesmos não acompanham o crescimento dageração de resíduos pelos brasileiros (RIBEIRO, 2015).

Além disso, a diferença entre o crescimento do resíduo e o crescimento populacionalmostra que o brasileiro tem consumido mais e isso somente evidencia a urgência daotimização do tratamento do lixo no Brasil; da interferência do designer para desenvolverprodutos mais sustentáveis; e dos demais setores sociais e privados em estimular uma culturasustentável no país (RIBEIRO, 2015).

Para a amenização do problema do lixo, o governo deve investir e incentivar medidassustentáveis. Segundo a ABRELPE (2016), pouco se tem investido (cerca de $2 \%$ do PIBanual de 2014) na área de saneamento e infraestrutura. Isto diminui, consequentemente, aschances de criação de ferramentas que estimulem as mudanças e façam com que o grau deaceitação de medidas ambientais seja maior, conforme preconizam Manzini e Vezzoli (2005).

Além disso, para que exista uma unificação no sistema de tratamento de resíduos sólidosbrasileiro, o país deveria investir cerca de R\$11,6 bilhões até 2031 (ABRELPE, 2016).

Conclui-se, de forma geral, que o Brasil ainda caminha lentamente em direção a um sistemade coleta sustentável. O caminho para uma melhor administração do resíduo e a adoção cadavez maior de uma consciência sustentável por parte da sociedade brasileira deve acontecer emum ciclo, onde todos os setores estão dispostos a adotar medidas para contribuir com isso.Com o objetivo de aprofundar na problemáticado destino do resíduo, foirealizada uma visita técnica ao aterro sanitário da Companhia de Saneamento do Paraná(SANEPAR) no município de Cianorte no 
Estado do Paraná, Brasil. A SANEPAR é aempresa responsável pela coleta de lixo e tratamento de resíduos sólidos no referidomunicípio. O aterro sanitário da cidade de Cianorte é exemplo nacional de tratamento do lixo,tendo iniciado suas atividades em 2002. Sua área total é de 15,54 ha e atende aaproximadamente 70 mil habitantes do município. Possui certificação ISO 31000 e NBR ISSO 14001:2004, normas de excelência nacional com relação a tratamento de resíduos sólidos(SANEPAR, 2015). Marcio Benites era o responsável químico pelo aterro sanitário nomomento da visita.Naquela oportunidade, houve esclarecimentos sobre o funcionamento e coleta deresíduos permeando aspectos referentes à coleta de resíduos sólidos, especificamente oschinelos de borracha. Segundo Benites um dos maiores problemas enfrentados é o lixoinadequado que chega ao aterro prejudicando todo o processo. Esse lixo pode ser: lixoreciclável, entulho e materiais de difícil decomposição ou que possuem destinos específicosapós o descarte. Entre esses materiais está a borracha que possui tempo indeterminado dedecomposição na natureza (BENITES, 2015).

Os resíduos de borracha são considerados resíduos sólidos. A NBR 10004, queclassifica resíduos sólidos quanto as suas características para serem gerenciados de formacorreta e com o mínimo de impacto no meio ambiente, menciona que os resíduos sólidos sãotodos aqueles sólidos ou semissólidos originários da indústria, atividades domésticas,hospitalares, comerciais, agrícolas e de serviço de varrição (ABNT, 2004). Estes resíduos sãoclassificados como não perigosos quanto a sua toxidade em relação a organismos vivos.

Segundo a cartilha do Plano Nacional de Resíduos Sólidos (PNRS), elaborada peloGoverno Federal Brasileiro, o gerenciamento de resíduos sólidos deve ser realizado tantopelas indústrias quanto pela população. Na cartilha percebe-se a preocupação com as questõesambientais e com o impacto ambiental dos resíduos gerados por toda a sociedade brasileira(ALMEIDA, 2014).

Dentre os objetivos do PNRS, estão (ALMEIDA, 2014):

- Preservação do meio ambiente e saúde do Brasil;

- Incentivar à prática de padrões sustentáveis na produção e no consumo;

- Diminuir o volume e a periculosidade de resíduos sólidos;

- Estimular a redução, reutilização, reciclagem e tratamento dos resíduos sólidos, além de criar destinos adequados aos resíduos.

Por fim, Benites incentiva a reciclagem de resíduos de chinelos descartados, já que osmesmos não são valorizados pelas cooperativas de reciclagem e nem são adequadamentedescartados quando destinados a aterros. Porém, ressalta que a melhor forma de recolher assandálias de borracha descartadas seria com a separação pela própria população como é feitocom o lixo eletrônico, visto que o lixo que chega ao aterro não pode ser manuseado. Ressaltatambém que a separação pelo próprio usuário ou o recolhimento por algumaentidade/cooperativa nas casas dos consumidores antes do produto ser jogado no lixo poderia ser uma ação mais econômica e saudável.

\section{Papel Ressignificador do Design Sustentável}

Para Manzini e Vezzoli (2005), o termo ecodesign liga a ação de projetar e o ambiente para o qual se projeta tornando a preocupação com o meio ambiente uma característica intrínseca a esse tipo de projeto. Somam-se a isto as dimensões sociais e econômicas que aproximam 
produtos e/ou serviços de soluções mais sustentáveis.

Mesmo sendo amplamente discutidas por diversas áreas, as noções de sustentabilidade e, mais especificamente na área de ciências sociais aplicadas, as noções de ecodesign muitas vezes são tratadas de forma superficial. Nota-se que há uma preocupação cada vez maior com o impacto causado no meio ambiente e tal preocupação torna necessária a criação de políticas mais limpas, tecnologias que agridem menos o meio ambiente, mas principalmente, mudanças culturais e uma forma de projetar produtos levando em conta tais questões. Manzini e Vezzoli (2005) dizem que apenas a criação de processos produtivos mais limpos e medidas paliativas, não são suficientes para que haja uma mudança profunda na sociedade para um caminho mais sustentável. São as transformações culturais e de valores que geram tais mudanças. Portanto, as mudanças devem seguir primeiramente medidas paliativas em um curto prazo, mas no longo prazo, as medidas devem ser um reflexo de uma mudança social e cultural. Existem quatro níveis de medidas a serem tomadas com relação ao ecodesign (MANZINI E VEZZOLI, 2005):

No primeiro nível, o que acontece é uma mudança apenas na parte técnica dos produtos e serviços, como por exemplo, em seus materiais, a fim de otimizar o processo produtivo e lucro de vendas, fato que torna o produto competitivo diante do consumidor. Porém, o produto não possui impacto no aspecto cultural, visto que apenas componentes e processos produtivos são alterados, mas o produto continua sendo basicamente o mesmo. Esse nível é o mais explorado pela indústria e é conhecido como redesign;

No segundo nível, os produtos e serviços são desenvolvidos desde o ponto inicial e projetados com foco na sustentabilidade e facilidade de aplicação, porém, existem poucas iniciativas com esta perspectiva. Alguns exemplos são os carros elétricos, alimentos, produtos corpóreos, etc. É possível notar que esses produtos foram desenvolvidos de acordo com a mudança cultural rumo à sustentabilidade, mas a capacidade de transformações culturais é consequentemente menor que os níveis mais profundos de ações sustentáveis;

No terceiro nível, o desafio é grande para os projetistas e empresas, pois o produto ou serviço deve ser radicalmente sustentável e aceitável culturalmente. Produtos ou serviços como estes devem ser projetados de forma cautelosa, pois representam riscos. Por um lado se não aceitos socialmente, vão representar um prejuízo, mas se bem recebidos pelo usuário, eles possuem um diferencial natural contra todos os seus concorrentes. É possível ver que esse tipo de mudança requer muito empenho, mas são medidas que podem ser consideradas as mais congruentes com a sustentabilidade;

O quarto nível diz respeito às mudanças socioculturais para criar novos cenários para o desenvolvimento sustentável. Isso pode ser feito através de pesquisas do âmbito acadêmico como artigos, livros, eventos, etc. e empresas dispostas a se tornar transformadoras culturais.

Atualmente a indústria fica limitada aos dois primeiros níveis de medidas a serem tomadas com relação à sustentabilidade. Esses níveis são importantes para reduzir os impactos ambientais existentes, porém, para se atingir resultados mais sustentáveis, é preciso alterar níveis mais profundos como transformações do consumo e mudanças socioculturais (MANZINI e VEZZOLI, 2005).

Por outro ponto de vista, Cardoso (2013) menciona que o acúmulo do lixo é um reflexo de como a sociedade em geral trata os artefatos e que a significação de um objeto pode ser algo 
muito instável. Uma comparação interessante seria entre as embalagens e um automóvel. Ambos os produtos passaram por um processo de design, porém, o significado e valor agregado que são impressos nestes produtos alteram o modo como tratamos os mesmos. O designer tem um papel de ressignificador dos objetos descartados. O ponto principal ao qual o designer tem poder é em dar significados aos artefatos, materiais e processos. Pode-se concluir que o designer é responsável por alterar a visão do que é considerado lixo (CARDOSO, 2013).

Por fim, esta pesquisa procurou reaproveitar um resíduo, considerado sem valor pela sociedade e sem consenso de qual a destinação correta, no desenvolvimento de um novo material passível de utilização pelo design de produtos. Neste sentido, propôs-se agregar valor ao resíduo da borracha de chinelos descartados por meio da criação de um novo material, projetando novos significados e soluções para o problema dos resíduos de borracha.

\section{Método de Pesquisa}

Tendo sido utilizado em Projeto de Pesquisa Institucional, o método de pesquisa apresentado aqui é idêntico a de Forcatoet al. (2017) já que se trata da mesma pesquisa. Neste sentido, repete-se neste artigo as etapas metodológicas apresentadas naquela ocasião.

De acordo com Gil (1999, p.33), esta pesquisa possui Método Experimental por que submete "objetos de estudo à influência de certas variáveis, em condições controladas e conhecidas pelo investigador". Além disso, pode ser classificada como exploratória e aplicada, pois explora resultados aproximados de um tema ainda pouco explorado, bem como seus resultados podem ser aplicados em situações reais.

Para a execução da pesquisa, foram definidas 8 etapas de trabalho, as quais estão descritas a seguir:

A primeira etapa consistiu da Revisão Bibliográfica acerca de dados sobre a indústria da borracha e calçadista, bem como, aspectos inerentes ao Design Sustentável e a esta pesquisa. Foi realizada Revisão Bibliográfica Simples em livros, periódicos e sites especializados.

A etapa seguinte culminou na primeira Recolha de Material, em baixa escala, com o intuito de observar diferenças físicas entre chinelos de borracha de marcas diferentes. O objetivo foi adquirir material para apoiar as etapas seguintes no que concerne a diferenciação dos materiais em diversos tipos/marcas de chinelos, na intenção de padronizar os resíduos de borracha pesquisados. A recolha ocorreu em um condomínio onde os moradores deixavam os chinelos em um ponto de coleta. Como resultado, esperava-se pelo menos recolher chinelos das duas principais marcas vendidas no Brasil .

A etapa de número três compreendeu a Identificação dos Materiais por meio da observação do comportamento mediante queima e submersão em água e solvente. O objetivo foi detectar congruências químicas e físicas nos resíduos de chinelos de duas marcas no intuito de compreender se seria possível utilizar os diversos tipos de resíduos gerados pela sociedade por meio dos chinelos de borracha descartados. Além disso, os resíduos foram comparados com amostras pré-concebidas constituídas por "pó de borracha de chinelo da marca Havaiana + cola branca". O processo de identificação por queima dos materiais ocorreu por observação da cor da chama, consequências da queima no material (carbonização, gotejamento, aborbulhamento), presença e cor da fumaça, presença de fuligem, tempo de queima e cheiro. Como instrumento de confirmação, foram utilizados os preceitos de Lima (2013). 
Na quarta etapa foram realizados os Primeiros Testes de Colagem dos resíduos. O objetivo foi juntar os resíduos para a produção de placas de borracha. Vários testes foram propostos nesta etapa, os quais propunham a utilização de aglutinantes artificiais e de origem vegetal na união de pedaços da borracha do chinelo; pedaços de chinelos com pó da borracha do chinelo; e somente pó da borracha do chinelo. Entre os aglutinantes artificiais testados foram utilizados cola branca da marca Cascorez, cola epóxi da marca Araudite, cola de silicone da marca TekVed e gesso. Os aglutinantes de base vegetal testados foram o poliuretano vegetal da marca Imperveg, o aglutinante bi componente da marca Kehl e o aglutinante ecológico à base d'água da marca Adespec. Este artigo apresentará apenas os resultados obtidos com o aglutinante da marca Kehl, Imperveg e Cola Branca.

A quinta etapa consistiu da Recolha do material em larga escala. O objetivo desta foi recolher quantidade suficiente de material para confecção de corpos de prova de três materiais experimentais. Esta etapa envolveu a comunidade no projeto e promoveu a conscientização dos usuários de chinelos de borracha sobre o ciclo de vida do produto e da possibilidade de descarte adequado. Foi realizada campanha de coleta de chinelos em um campus universitário e promovido por meio de rede social, cartazes e postos de coleta distribuídos pelo campus.

Na sequência, foi proposto a redução a pó dos chinelos da marca "Havaianas" para a Confecção de Corpos de Prova. Buscou-se utilizar somente aglutinantes vegetais e cola branca no intuito de minimizar os impactos ambientais futuros e o objetivo da etapa foi realizar testes de resistência física e química controlados, tais como de resistência à tração e compressão, bem como de absorção de água e de temperatura.

Em laboratório específico para testes de materiais, a sétima etapa consistiu justamente dos Testes Mecânicos de tração e compressão com os novos materiais. O intuito foi identificar as principais características e propriedades dos novos materiais com objetivo de se obter dados para indicar possíveis aplicações do material em produtos de design. Utilizou-se como equipamento o Sistema Universal para testes de tração, compressão e flexão da marca EMIC constituído por Máquina Universal Série 23 e Estrutura de $2.000 \mathrm{kN}$.

A última etapa consistiu de um processo de design que sugeriu a aplicação do novo material um produto.

No capítulo seguinte será apresentado e discutido apenas recorte dos resultados obtidos, Em outras palavras, somente àqueles obtidos pelas amostras (corpo de prova) que utilizou o aglutinante bi componente da marca Kehl e o aglutinante vegetal da marca Imperveg e mistura dos resíduos com cola branca. Estes foram os que apresentaram melhores resultados nos testes mecânicos.

\section{Resultados e Discussão}

O aglutinante bi componente da marca KEHL possui em sua composição, componentes renováveis como óleos de origem vegetal que não causam impactos negativos no meio ambiente (KEHL, 2016). A empresa Kehl atuou como parceira fornecendo os aglutinantes para o projeto.

Após vários testes foi possível verificar que a concentração que promove um melhor resultado compreende volumes iguais dos componentes, por exemplo, uma medida de pó de borracha e a mesma medida do aglutinante. A secagem ocorre rapidamente após expansão do material. O material resultante é poroso, leve, com densidade de $0,5 \mathrm{~g} / \mathrm{cm}^{3}$ e resistente. A 
coloração do aglutinante, de cor marrom claro, afeta sutilmente o resultado visual do material final, de acordo com a cor de borracha que se utiliza (Figura 4).

Figura 4 - Corpos de prova (aglutinante Kehl)

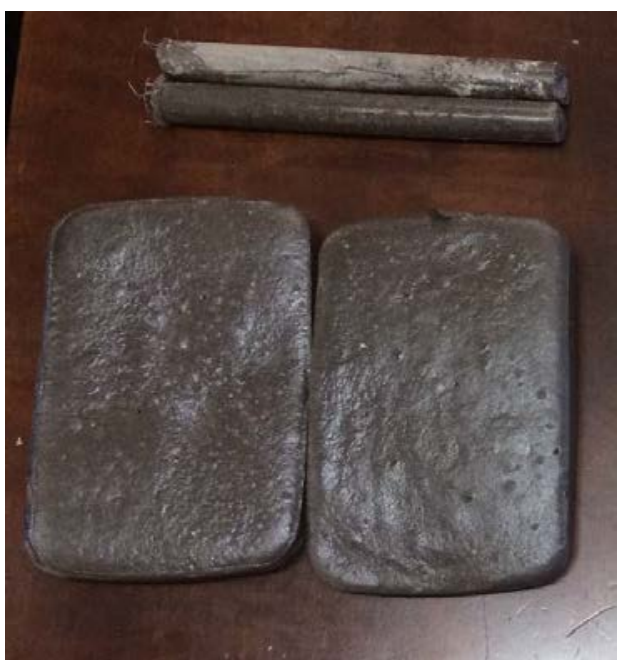

Fonte: Elaborado pelos autores (2016).

Foram realizados ensaios de tração e compressão com amostras do material. No teste de tração, a amostra cilíndrica com aglutinante Kehl suportou uma força máxima de $1180 \mathrm{~N}$ e teve um alongamento de $4,11 \%$ até a ruptura. É possível que a presença de bolhas de ar na estrutura interna do material tenha comprometido sua resistência. No teste de compressão foi constatado que a amostra em forma de paralelepípedo com $20 \mathrm{~cm}$ de altura, $10 \mathrm{~cm}$ de comprimento e $2 \mathrm{~cm}$ de espessura suportou até $10543,45 \mathrm{~N}$ o que equivale a $1075,8 \mathrm{~kg}$.

Em teste hidroscópico, a amostra de 97 gramas ficou submersa em água por 24 horas, sendo que neste período, seu peso aumentou em 1 grama, demonstrando baixa capacidade de absorção mesmo sendo um material bastante poroso.

O segundo material utiliza em sua composição o aglutinante da marca Imperveg que atua no desenvolvimento e fabricação de resinas a base de poliuretano vegetal que são obtidas do processamento químico do óleo de mamona (IMPERVEG, 2016). Para a produção do corpo de prova, também foram utilizadas medidas igual dos materiais borracha e a aglutinante. A mistura do pó com aglutinante da empresa IMPERVEG resultou em um material com boa resistência a aplicação deforças manuais, leve, com densidade de $0,5 \mathrm{~g} / \mathrm{cm}^{3}$, rígido, com uma coloração e acabamento altamente manipulável. Em contra partida, o material durante sua secagem tem um processo de expansão muito rápido, formando muitas bolhas de ar. Este aspecto pode dificultar o desenvolvimento do material em moldes onde não há espaço para a oxigenação (Figura 5).

No ensaio de tração, em uma força máxima de 316,71N a amostra IMPERVEG teve um alongamento de $4,07 \%$ até a ruptura. Pela grande presença de bolhas ar (algumas delas muito grandes) o teste de tração não obteve resultados confiáveis. No teste de compressão foi constatado que a amostra com $20 \mathrm{~cm}$ de altura e $10 \mathrm{~cm}$ de comprimento e $2 \mathrm{~cm}$ de espessura suportou até $12282,57 \mathrm{~N}$ o que equivale a $1253,5 \mathrm{~kg}$. No teste hidroscópico a amostra também teve seu peso aumentado em 1 grama, o que também demonstra a baixa capacidade de absorção 
de água.

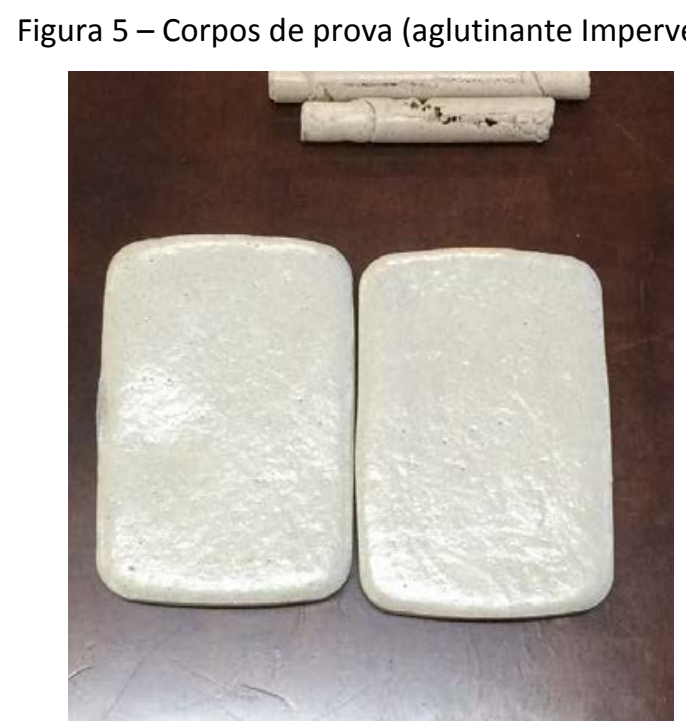

Fonte: Elaborado pelos autores (2016).

Comparado a outros materiais já conhecidos, este material experimental se assemelha ao poliuretano expandido, em densidade e possibilidades de aplicação. Ainda assim, vale lembrar que a composição do aglutinante tem origem vegetal e é de baixo impacto ambiental, amenizando agressões por substâncias voláteis e por componentes artificiais. Além disso, utilizou na composição um resíduo de borracha,convencionalmente,sem tipologia de descarte definida e baixa probabilidade de reciclagem.

Com relação à mistura do resíduo da borracha com cola branca, obteve-se um material parecido com o dos chinelos descartados. Sua densidade é de $0,7 \mathrm{~g} / \mathrm{cm}^{3}$. No teste de tração apontou grande elasticidade, sendo que o seu comprimento inicial de $18 \mathrm{cmchegou}$ a aproximadamente $25 \mathrm{~cm}$, utilizando uma força máxima aplicada pelo maquinário de 143,96N no estiramento.Não houve rompimento já que a amostra escapou devido a diminuição de seu diâmetro, causado pelo estiramento.Foi constado depois de duas semanas que o comprimento retornou muito próximo do original ficando com $21 \mathrm{~cm}$. Isto mostra a capacidade de resiliência deste material. Quando submerso em água (por 24h), o material amolece podendo ter sua geometria levemente alterada se houver pressionamento constante. Neste período, a amostra passou de $127 \mathrm{~g}$ para $137 \mathrm{~g}$, demonstrando hidroscopia moderada. Depois de seco, recupera as mesmas propriedades.

Esta característica torna os resultados do material com cola branca muito interessantes, porém, não possibilita sua comparação com outros materiais, já que não estão completos. Devido à elasticidade e maleabilidade, não foram realizados ensaios de compressão com a amostra com cola branca.

\subsection{Proposições de Aplicação em Design de Produtos}

Com os resultados obtidos, principalmente força máxima e alongamento da ruptura, foram realizadas comparações com alguns polímeros e espumas provenientes de polímeros disponíveis na literatura.Utilizando-se da ferramenta brainstorming foram sugeridas diversas aplicações 
possíveis dos novos materiais em Design de Produtos.

Para a mistura com cola branca, por sua elasticidade,foram consideradas sua aplicação em brinquedos (porém testes futuros de toxidade devem ser realizados), material de reforço quando misturados com outros polímeros ou outros tipos de material, ou como revestimento para área interna. Como há a possibilidade de utilização de cores sem mistura, é possível que haja aplicação de efeitos visuais interessantes e composições com cores variadas nesta opção.

As misturas com os aglutinantes da marca Kelh e Imperveg apresentaram alta leveza, resistência similar a alguns polímeros e espumas de polímeros, por isso, foi considerada sua aplicação como material para vedação, blocos para prototipagem, joias, piso antiderrapante, revestimento para decoração, móveis pré-moldados, objetos em geral, cenografia, painéis prémoldados para construção civil, mobiliário externo, módulos para jardim suspenso, etc.

Ainda é necessário explorar as capacidades destes materiais podendo haver uma gama muito grande de possibilidades de aplicação.

\section{Conclusão}

Tendo em vista o descarte inadequado pelos usuários dos resíduos de chinelos, bem como a ausência de consenso sobre qual a melhor forma de descarte, este trabalho buscou explorar foras viáveis e de baixo impacto de coleta, transformação e reinserção deste material no design de produtos. Isso tudo, por meio do caráter transformador do designer como ressignificador de objetos e materiais.

O ciclo de vida de um produto é um aspecto importante que demanda o comprometimento do designer como um agente também responsável pela transformação social, econômica e ambiental de uma cadeia de produção. Desde o inicio de um projeto, o designer deve levar em consideração a influência que possui sobre os caminhos de um projeto que irá resultar em um menor o impacto ambiental e incentivar o usuário a complementar esse ciclo sustentável de um produto, como o uso adequado e o descarte consciente.

Com os resultados obtidos, pode-se mostrar que o designer também tem um papel de transformador social, ambiental e econômico. O design sustentável propõe que o profissional possa olhar com maior comprometimento todo o ciclo de vida de um produto, projetando para que tudo possa resultar em um menor impacto ambiental e influenciar até mesmo o comportamento do usuário, incentivando-o a praticar o descarte de forma mais correta e consciente.

Os materiais propostos neste artigo ainda devem passar por estágios de refinamento em seu desenvolvimento. Nestes estágios, sugere-se adotar alternativas e procedimentos para diminuir a quantidade e tamanho de bolhas de ar no material aumentando assim sua resistência. É importante que se façam novos estudos para identificar outras possibilidades de composição com este resíduo, tais como: novos aglutinantes; outros formatos de inserção da borracha (grânulos maiores e pedaços de tamanhos variados). Portanto serão necessários novos ensaios, com corpos de prova mais precisos e confeccionados de maneira mais apropriada; além de estudar o impacto ambiental dos novos materiais e a avaliação de outras propriedades como capacidades térmicas e acústicas.

Por fim, não devem ser tomados como solução final os resultados aqui apresentados no 
que concerne à destinação, aproveitamento, reciclagem/reutilizaçãodos resíduos de chinelos descartados. No entanto, sugere-se que esta iniciativa possa ser tomada como inspiração para processos de criação e experiências que envolvam os materiais estudados e outras aplicações em projetos de design que, como afirmam Ashby e Johnson (2011), além de exercerem grande influência no design, novos materiais serão muitas vezes o ponto de partida para novos produtos e inspiração para formatos e características nunca exploradas antes.

\section{Referências}

ASSOCIAÇÃO BRASILEIRA DE NORMAS TÉCNICAS. NBR 10004: Resíduos sólidos - Classificação. Rio de Janeiro: ABNT, 2004. 77 p. Disponível em: <http://www.videverde.com.br/docs/NBR-n-100042004.pdf>. Acesso em: 31 jan 2016.

ABRELPE. Estimativa dos Custos para Viabilizar a Universalização da Destinação Adequada de Resíduos Sólidos no Brasil. Disponível em:<http://www.abrelpe.org.br/estudo_apresentacao.cfm>. Acesso em: 18 mai 2016.

ALMEIDA, Ana Carla. Plano de Resíduos Sólidos: Responsabilidade Socioambiental na Administração Pública. Brasília: Secretaria de Articulação Institucional e Cidadania Ambiental, 2014. 64 p.

Disponívelem:<http://www.comprasgovernamentais.gov.br/arquivos/cartilhas/cartilha_pgrs_ mma.pdf $>$. Acesso em: 31 jan 2016.

ASHBY, M. JOHNSON, K. Materiais e Design: arte e ciência da seleção de materiais no design de produto.2ed. Rio de Janeiro: Elsevier, 2011.

BENITES, Marcio. Visita ao aterro sanitário da SANEPAR. [dec. 2015]. Entrevistador: ORTIZ, Guilherme: Universidade Estadual de Maringá, 2015.

BRASIL. MINISTÉRIO DO TRABALHO E EMPREGO. Bases estatísticas RAIS/ Caged. Disponível em: <http://sgt.caged.gov.br/index.asp>. Acesso em: 14 dez 2009.

CARDOSO, Rafael. Design para um mundo complexo. São Paulo: Cosacnaify, 2013. 262 p.

ORTIZ, Guilherme Clausem. Reutilização da borracha sintética de chinelos descartados no design de produtos. 2016. 198 f. Monografia (Graduação) - Curso de Design, Universidade Estadual de Maringá, Cianorte, 2016.

FORCATO, M. S.; DIAS, J. L.; DALBERTO, A. G.; ORTIZ, G. C. A borracha sintética de chinelos descartados no design de produtos. Design, ArtandTecnology - DAT Journal. v.2, n.2,p. 03-18, dez 2017.

FORREST, Martin. RecyclingandRe-useofWaste Rubber. [s.i.]: SmithersRapra Technology, 2014. Cap. 3. p. 17-30. Disponível em: <http://www.smithersrapra.com/SmithersRapra/media/SampleChapters/Recycling-and-Reuse-of-Waste-Rubber.pdf>. Acesso em: 31 jan 2016.

GARLET, Givanildo. Aproveitamento de Resíduos de E.V.A. (EthyleneVinylAcetate) como agregado para concreto leve na construção civil. 1998. 162 f. Dissertação (Mestrado) - Curso de Engenharia Civil, Universidade Federal do Rio Grande do Sul, Porto Alegre, 1998. Disponível em:<https://www.lume.ufrgs.br/bitstream/handle/10183/118243/000226272. pdf? sequence=1 $>$. Acesso em: 26 jan 2016.

GIL, Antônio Carlos. Métodos e técnicas de pesquisa social. São Paulo: Atlas, 1999. 
GLOBALRUBERMARKETS. SBR willreach 141.5 billionyuan trading. 2014. Disponível em: <http://globalrubbermarkets.com/19138/sbr-will-reach-141-5-billion-yuan-trading.html>. Acesso em: 28 jan 2016.

GUIDOLIN, Silvia Maria; ROCHA, Érico Rial Pinto da; COSTA, Ana Cristina Rodrigues da.BNDES:indústria calçadista e estratégias de fortalecimento da competitividade. 2010.Disponível em:

<http://www.bndes.gov.br/SiteBNDES/export/sites/default/bndes_pt/Galerias/Arquivos/conheci mento/bnset/set3104.pdf>. Acesso em: 1 mar 2016.

IMPERVEG. Família de Resinas. Disponível em: <http://imperveg.com.br>. Acesso em: 06jul 2016.

KEHL. Aglomerantes. Disponível em:<http://www.kehl.ind.br/poliuretanos.php?opcao=agl>. Acesso em: 07 jul 2016.

LIMA, Marco Antonio Magalhães. Introdução aos materiais e processos para designers.3ed.Rio de Janeiro: Editora Ciência Moderna, 2013. 225 p.

MANZINI, Ezio; VEZZOLI, Carlo. O desenvolvimento de produtos sustentáveis. São Paulo: Editora da Universidade de São Paulo, 2005. 345 p.

MCDONOUGH, William; BRAUNGART, Michael. Cradletocradle:remakingthewaywemakethings. New York: North Point Press, 2002.

MUCAMBO. Um pouco da história da borracha. São Paulo, 2015. Disponível em: <http://www.mucambo.com.br/pdfs/historiadaborracha.pdf >. Acesso em: 19 jan 2016.

NUNES, Ilson. A reciclagem da borracha: entrevista. 2015. São Paulo: Revista BorrachaAtual. Entrevista concedida à Associação Brasileira de Tecnologia da Borracha (ABTB).

PAIVA, Roberto. Apenas 3\% de todo o lixo produzido no Brasil é reciclado. 2015.Disponível em: <http://g1.globo.com/jornal-hoje/noticia/2015/04/apenas-3-de-todo-o-lixoproduzido-no-brasil-ereciclado.html>. Acesso em: 18 mai2015.

PAPAUTSKY, David. Borracha: Recuperação e Regeneração. São Paulo: Ponto Quatro,2003.

RIBEIRO, Stênio. Produção de lixo no país cresce $29 \%$ em 11 anos, mostra pesquisa. 2015. Disponível em: <http://agenciabrasil.ebc.com.br/geral/noticia/2015-07/producao-delixo-no-paiscresce-29-em-11-anos-mostra-pesquisa-da-abrelpe>. Acesso em: 18 mai 2015.

SANEPAR. Aterro sanitário de Cianorte.Disponível em: <http://site.sanepar.com.br/noticias/categoria-desta-noticia/cianorte>. Acesso em: 02 abr2018.

STATISTA. Global consumptionof natural andsynthetic rubber from 1990 to 2015 (in1,000 metric tons). Disponível em: <http://www.statista.com/statistics/275399/worldconsumption-of-naturaland-synthetic-caoutchouc/>. Acesso em: 27 jan 2016.

Agradecimentos: Às empresas Imperveg e Kehl pela parceria e contribuição nesta pesquisa e à Coordenação de Aperfeiçoamento de Pessoal de Nível Superior - CAPES pelo apoio financeiro no processo de doutoramento. 